\title{
К ВОПРОСУ О ВЛИЯНИИ COVID-19 НА НЕВРОЛОГИЧЕСКИЙ И ПСИХИЧЕСКИЙ СТАТУС
}

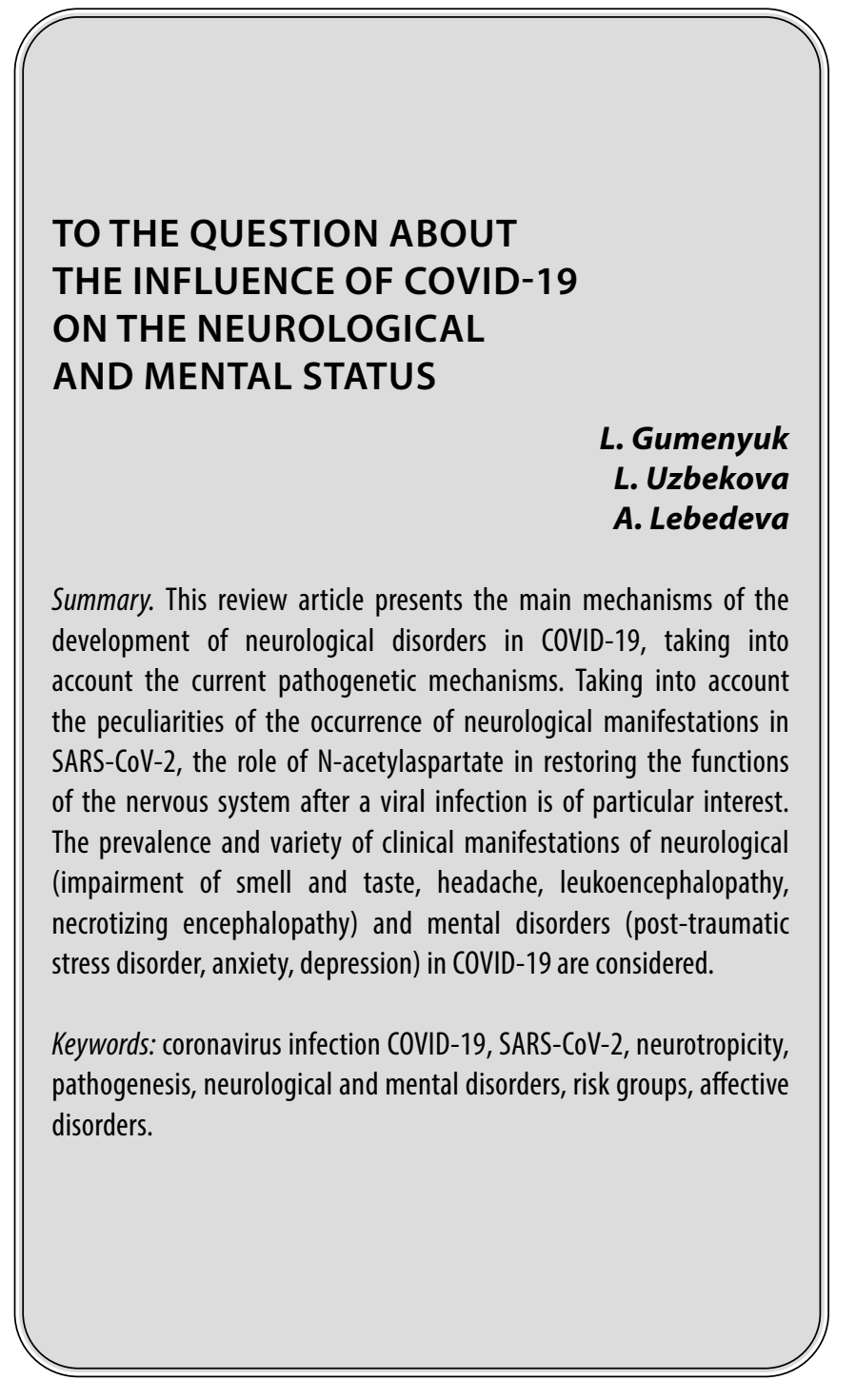

\section{Введение}

ARS-CoV-2 (severeacuterespiratorysyndromecorona virus 2) - новый штамм коронавирусов, выявленный в конце 2019 года, индуцирующий опасное инфекционное заболевание - CoronaVirusDisease 2019 (COVID-19) [17]. Начавшись с единичного случая заболевания на рынке морепродуктов в Ухани (КНР), инфекция стремительно распространилась по миру, охватив практически все государства [53]. После глобального распространения SARS-CoV-2, BO3 объявила COVID-19 чрезвычайной ситуацией в области здравоохранения, имеющей международное значение [58].

\author{
Гуменюк Леся Николаевна \\ Д.м.н., профессор, Медицинская академия имени \\ С.И. Георгиевского (структурное подразделение ФГАОУ \\ ВО «КФУ им. В.И. Вернадского») \\ lesya_gymenyuk@mail.ru \\ Узбекова Лейла Джавадовна \\ Медицинская академия имени С.И. Георгиевского \\ (структурное подразделение ФГАОУВО «КФУ \\ им. В.И. Вернадского») \\ leila1998.999@mail.ru \\ Лебедева Анна Михайловна \\ Медицинская академия имени С.И. Георгиевского \\ (структурное подразделение ФГАОУВО «КФУ \\ им. В.И. Вернадского») \\ anna96lebedeva@yandex.ru
}

Аннотация. В данной обзорной статье представлены основные механизмы развития неврологических расстройств при COVID-19 с учетом актуальных патогенетических механизмов. Учитывая особенности возникновения неврологических проявлений при SARS-CoV-2, особый интерес представляет роль $\mathrm{N}$-ацетиласпартата в восстановлении функций нервной системы после перенесенной вирусной инфекции. Рассматривается распространенность и многообразие клинических проявлений неврологических (нарушение обоняния и вкуса, головная боль, лейкоэнцефалопатия, некротизирующая энцефалопатия) и психических расстройств (посттравматическое стрессовое расстройство, тревога, депрессия) при (OVID-19.

Ключевые слова: коронавирусная инфекция COVID-19, SARS-CoV-2, нейротропность, патогенез, неврологические и психические нарушения, группы риска, аффективные расстройства.
Согласно данным ряда современных исследователей, пандемия COVID-19, имеющая высокий стрессогенный потенциал, помимо угрозы для физического здоровья и жизни людей, параллельно спровоцировала рост нарушений нервно- психического здоровья [32]. По мнению М.Ю. Сорокина и соавт. [4], в условиях пандемии возникли условия, при которых единовременно присутствует ряд факторов, оказывающих влияние на психическое здоровье: беспрецедентная потенциально угрожающая жизни ситуация с неопределенной продолжительностью; глобальные карантинные меры, ограничивающие личную свободу; неопределенность длительности инкубационного периода инфицирова- 
ния SARS-CoV-2 и его бессимптомной передачи; уведомления о дефиците медицинских средств защиты и лекарственных препаратов; неустойчивая информационная картина с переизбытком противоречивой информации; неопределенность, сцепленная с влиянием COVID-19 на экономическую ситуацию.

Психологические реакции на опасность по большей части универсальны и это дает возможность предположить, что психоэмоциальный ответ людей в условиях пандемии COVID-19 будут аналогичны таковым в других чрезвычайных ситуациях. Вместе с тем, переживание пандемии различными социальными группами может иметь свои особенности. В связи с тем, что неврологические и психические расстройства значительно снижают самооценку, социальное функционирование и качество жизни, оказывают негативное влияние на привычный ритм жизни, обусловливая возникновение конфликтных ситуаций и формирование отрицательного статуса личности [5], в данной обзорной статье мы уделили особое внимание возможным патогенетическим механизмам, лежащим в основе связи между COVID-19 и поражением нервной системы, структуре неврологических и психических расстройств, группам риска развития (усугубления) неврологических и психических расстройств.

\section{Патогенез поврежАения нервной системы вирусOм SARS-COV-2}

Вирус SARS-CoV-2 имеет прямое действие на нервную систему [60]. В научной литературе выделяют следующие причины поражения нервной системы: прямое избирательное влияние вируса на краниальные нервы и ткань мозга; экспрессия вирусом нейротоксинов; интенсификация вирусом воспалительных нейромедиаторов; миграция вируса в эндотелий церебральных сосудов и интрузия в мозговые структуры; вторичное повреждение в результате подострых/ острых аутоиммунных процессов.

Внедряясь и размножаясь в эпителиальных клетках носовой полости и носоглотки, вирусы по аксонам терминальных ветвей перемещаются в нейроны II, V, VII черепно-мозговых нервов [62]. В качестве барьера на пути к оболочках и структурным элементам головного мозга выступает местный иммунный ответ в зоне взаимодействия вируса с рецепторами ангиотензинпревращающего фермента 2 (АПФ2) и TMPRSS2. Посредством белка шипов S, вирус SARS-CoV-2 прикрепляется к клеткам, а фурин и TMPRSS2 облегчают его попаданию внутрь $[1,11,57,61]$. При дисфункциональности местного клеточно-куморального ответа, мутации G758R в белке $S$, трансформирующей вирусное распространение и нейровирулентность, вирусы и их токсины способны проникать через гематоэнцефалический барьер в сосудистую сеть, оболочки и кору головного мозга, базальные ганглии и ствол мозга $[25,34]$ с преимущественным поражением сосудов микроциркуляторного русла, обеспечивающих кровоснабжение зрительных бугров, субкортикальных и перивентрикулярных областей белого вещества больших полушарий. В пользу преодоления вирусом ГЭБ говорят данные аутопсии, а именно, обнаружение PHK SARS-CoV-2 в ликворе и паренхиме мозга [30, 33, 45]. Продвижение вируса к «мишени» происходит ретроградно, антероградно и транссинаптически по аксону и дентритам [16, 40, 42, 51].

При недостаточной активности клеточных защитных механизмов и интерферонов на начальном этапе инфицирования наблюдается местное, а затем и системное усиление экспрессии хемокинов и противовоспалительных цитокинов, что вызывает аутоантигенную агрессию и обусловливает цитопатическое повреждение клеток «мишени» [26]. Возникающий «цитокиновый шторм» повышает проницаемость ГЭБ и усиливает повреждающее действие вируса [8, 12, 29, 39, 52]. Вторичное повреждение коры, белого вещества больших полушарий, мозжечка и базальных ядер обусловлено водно-электролитным дисбалансом, гипоксией, ишемией мозга, инверсией метаболических изменений, вызванных пневмонией, анемией, вариабельностью систолического артериального давления.

В качестве значимых факторов инициации демиелинизации в ЦНС и периферической нервной системе авторами выделяются следующие: генетическая предрасположенность, гибель олигодендроцитов, нервных клеток и их отростков, интенсификация микроглии, аутосенсибилизирванных клонов клеточного звена иммунитета - CD4+, TM, TM7, активация TNF- $\alpha$, IL-4, IL-10 [15].

Многогранность механизмов повреждения и вовлеченность различных структур обусловливает многообразие клинических проявлений - от головной боли, лейкоэнцефалопатии, энцефалита, поперечного миелита до ведущих и атипичных форм синдрома Гийена-Барре.

\section{COVID-19 \\ и неврологические нарушения}

Нарушение обоняния, самый частый симптом, сопровождающий течение COVID-19. Это обусловлено тем, что слизистые оболочки полости носа более уязвимы, по сравнению с роговицей и конъюнктивой. Вирус COVID-19 проникает в нижнюю носовую раковину через слезно-носовой канал вместе со слезой из конъюнктивального мешка, а также в полость рта и носа при 
дыхании. Первые признаки поражения обонятельного нерва, как потеря запаха, при отсутствии ринореи, могут наблюдаться при хорошем самочувствии до проявления общеинфекционных признаков COVID-19. На это указывают данные, проведенного опроса 417 выздоровевших пациентов, у 357 (85,6\%) из которых наблюдалось нарушение обоняния. Причем у 88,2\% из них данный симптом возникал одновременно с общеинфекционными проявлениями, а у 11,8\% наблюдался на фоне отсутствия обще инфекционных симптомов COVID-19. Полная потеря обоняния наблюдалась у 79,6\% из 357 человек, а у 20,4\% наблюдалась лишь его снижение. После выздоровления полное восстановление обонятельной функции наблюдалось у всех респондентов со сниженным обонянием, а у тех, кто потерял запах полностью, он восстановился только у 67,8\% пациентов [35]. В настоящее время потерю обоняния предлагают признать в качестве надежного биомаркера COVID-19-инфекции.

При повреждении вирусом COVID-19 хеморецепторов сосочков языка, эпителия слизистой полости рта и глотки происходит нарушение вкуса. Далее вирус по афферентным нервным окончаниям краниальных нервов проникает в кору височных долей и ствол мозга, вызывая снижение, исчезновение или искажение вкуса $[2,14]$. Это подтверждают результаты опроса, по результатам которого снижение вкусовой чувствительности наблюдалось у 47,5\% опрошенных, полное отсутствие вкуса у 1,4-5,6\% и искажение вкуса у $21,1 \%$ респондентов с подтвержденной коронавирусной инфекцией. Данный симптом в 23,6-41,7\% случаях сочетался с потерей обоняния [23, 27, 56]. Восстановление функции вкусового анализатора происходило также почти полностью у респондентов с искажением и снижением вкуса, у лиц с отсутствием вкусовой чувствительности восстановление происходило гораздо медленнее, а в 34\% случаев вкус так и не восстановился [56].

Головная боль и слабость являются первыми симптомами со стороны ЦНС, при заболевании новой коронавирусной инфекцией. Этиология цефалгии в условиях пандемии COVID-19 достаточно вариабельна. Чаще всего головная боль возникает непосредственно от системного действия вируса COVID-19 на организм человека, что может быть обусловлено приемом лекарственных средств. Также цефалгия возникает на фоне астено-депрессивного состояния в условиях самоизоляции, и как проявление тревожно-фобических расстройств, вызванных своего рода ограничением свободы. Головная боль может возникать вследствие длительного ношения масок, респираторов и других средств индивидуальной защиты против коронавирусной инфекции, вызывающих гипоксию и физический дискомфорт [3].
Головная боль, как один из симптомов коронавирусной инфекции встречается у $12 \%$ респондентов, число которых по данным метаанализа 60 публикаций составило 3,5 тысячи. У медицинских работников головная боль встречается гораздо чаще. Об этом свидетельствует исследование, проведенное в Нидерландах. По его результатам получены следующие данные: из 803 сотрудников у 90 был диагностирован COVID-19 и у 71,1\% из них наблюдалась головная боль, но при этом у 41,5\% также отмечалась цефалгия с отрицательным результатом на COVID-19 [54].

Механизм системного действия вируса COVID-19, вызывающего цефалгию, заключается как в прямом действии вируса на клеточные структуры организма человека, так и опосредованно, запуская патологические процессы, посредством выброса иммуновоспалительных медиаторов и цитокинов [28]. Являясь триггером раздражения периваскулярных нервных окончаний тройничного нерва инерлейкин-1b (IL-1b), NF-kb (ядерный фактор kb), PGE2 (простагландин E2) и NO повышают ноцицептивную чувствительность рецепторов к медиаторам боли (брадикинину и гистамину) $[9,22]$. Одним из механизмов возникновения головной боли при коронавирусной инфекции является прямое внедрение вируса в окончания тройничного нерва, а в дальнейшем его повреждение. В результате возникают дисгевзия и аносмия, даже на ранней стадии инфекционного процесса $[10,36]$.

Сосудистый фактор - еще один механизм развития цефалгии при COVID-19, обусловленный вовлечением эндотелиальных клеток с высоким содержанием ACE2, активирующих тригеминоваскулярную систему.

В интенсивности головной боли важную роль играют степень выраженности воспаления и гипоксия, коррелирующие с тяжестью заболевания. На это указывают данные, полученные при исследовании пациентов с положительным диагнозом COVID-19 в Ухане. Чаще жалобы на интенсивную головную боль (17\%), предъявляли пациенты с тяжелым течением заболевания, чем больные с легким течением (10\%) коронавирусной инфекции $[36,43]$.

Оценить частоту встречаемости острого менингоэнцефалита, опираясь только на публикации, невозможно, так как случаев описано крайне мало. Острый менингоэнцефалит впервые был диагностирован у 24 летнего мужчины жителя г. Ухань с положительным диагнозом коронавирусной инфекции [41]. Через 9 дней после начала заболевания, интенсивная головная боль сменилась тронзиторными билатеральными тонико-клоническими судорогами и потерей сознания. Неврологический осмотр наличие очаговой симпто- 
матики не подтвердил, но зафиксировал регидность затылочных мышц. При исследовании в спинномозговой жидкости вирус обнаружен не был. Похожий случай, представленный М. Үе с соавторами, наблюдался у 28 летнего мужчины с схожими симптомами [63]. Виpyc COVID-19 в ликворе также не был обнаружен. Скорее всего, это связано с быстрой элиминацией вируса из СМЖ.

у детей с положительным диагнозом COVID-19 острый менингоэнцефалит также встречается, об этом свидетельствует случай 11-летнего ребенка, у которого ведущим симптомом была высокая утомляемость, другие симптомы отсутствовали. На ее фоне развился эпелептический статус [37]. У данного ребенка в ликворе была примесь крови, которой не наблюдалось в предыдущих случаях.

О возможности развития у больных коронавирусной инфекцией параинфекционного анти-NMDAR-энцефалита свидетельствует увеличение в ликворе интерлейкина 6 (IL6), антител к NMDA глутаматному рецептору, которые ведут к демиелинизации белого вещества головного мозга. Апоптоз, гибель олигодендроцитов, активация провоспалительных цитокинов (гамма-интерферона, IL1, IL6, IL12, трансформирующего ростового фактора бета) способствуют развитию иммуноопосредованного поражения определенных, наиболее подверженных эксайтотоксичности церебральных структур, что морфологически проявляется в виде лейкоэнцефалита [44].

Некротизирующая энцефалопатия является одной из редких осложнений коронавирусной инфекции, случаев ее описания крайне мало [16, 19, 20, 21]. Ее проявлением является размягчение мозга, выявляемое с помощью КТ и МРТ [31, 47]. Нейровизуализация показывает наличие кровоизлияний, как множественных рассеянных, так и сливных, распространенных симметрично или ограниченно в белом веществе височных долей, базальных ганглиях, островке, таламусе. Данные проявления обуславливает «цитокиновый шторм», приводящий к нарушению целостности гематоэнцефалического барьера, и инвазии вируса в головной мозг с последующей демиелинизацией мозговых структур $[38,46,47,61]$. «Цитокиновый шторм» также вызывает гемофагоцитарный лимфогистиоцитоз и имитирует острую некротическую энцефалопатию при COVID-19, полиорганной недостаточности, сепсисе, вследствие ДВС-синдрома [39].

Первый случай был описан у женщины 58 лет с положительным диагнозом COVID-19, на фоне полной симптоматики, подтверждающей коронавирусную инфекцию, отмечалось измененное психическое состо- яние. Сознание пациентки было спутанным, она была вялой и дезориентирована в пространстве. На КТ и МРТ были обнаружены признаки, подтверждающие некротизирующую энцефалопатию, в виде мелких кровоизлияний симметрично расположенных в таламусе, медиальных отделах височных долей и субостровковых областях. При введении контрастного вещества обнаружились признаки нарушения целостности ГЭБ в виде его кольцевидного накопления. После длительных диагностических мероприятий пациентке был поставлен диагноз - некротизирующая энцефалопатия. «Паттерн зон поражения и то, как прогрессировало заболевание день за днем, похожи на то, как это происходит при воспалении головного мозга вирусной природы. Это может значить, что в редких случаях вирус способен попадать прямо в головной мозг»,- сказала Элисса Фори «The New York Times» [35].

Краниальные мононевропатии при COVID-19 проявляются снижением, изменением или отсутствием запаха и вкуса, приступами непрерывного, насильственного, сухого и плохо купируемого кашля, першением в горле, болью при глотании, парастезиями, позывами на рвоту. Данные симптомы обусловлены повышенной чувствительностью ноцицепторов к медиаторам воспаления при сенсорной вирусной невропатии $[1,59]$. Это связано с механизмом проникновения вируса в обонятельный, тройничный, лицевой, языкоглоточный и блуждающий нервы, через поврежденные эпителиальные клетки полости рта, носа, слизистые оболочки глаз, верхние и нижние дыхательные пути, их повреждением и нарушением иннервации соответствующих участков лица и тела человека.

\section{COVID-19 и нарушения психического зАоровья}

В период пандемии в психической сфере у преимущественного числа людей, как реакция на стрессовые ситуации, возникают адаптивные эмоциональные и посттравматические стрессовые расстройства (ПТСР). Клинически ПТРС проявляется: чувством тревоги, страха, ночными кошмарами, бессонницей, постоянным чувством ожидания угрозы, раздражительностью, снижением внимания и памяти. Ко всему этому, меры ограничения свободы, вызывают чувство одиночества, разочарованности и бесперспективности, чувство социальной ограниченности, отчужденности, импульсивные решения бегства из находящихся на карантине населенных пунктов $[13,24]$. Результаты выполненных исследований в Китае показали, что у 30\% населения, оказавшихся изолированными, наблюдались симптомы выраженной тревоги, у 17\% - выраженной депрессии и у $35 \%$ - явные признаки ПТСР. При этом авторами указывается, что чаще вышеуказанные нарушения на- 
блюдались у женщин и лиц молодого возраста, обучающихся в средних и высших учебных заведениях.

В марте-апреле 2020 года в Италии проводили скрининговое исследование 18 тысяч человек, находящихся на 3-4 недельном карантине. Результаты были таковы, что симптомы ПТСР наблюдались у $37 \%$ респондентов, выраженный стресс был у 22,8\% опрошенных, у 21,8\% присутствовали расстройства адаптации, 20,8\% респондентов испытывали чувство выраженной тревоги, 17,3\% - депрессии, 7,3\% - бессонницы [49].

В США пандемия COVID-19 вызвала более существенные нарушения в психической сфере. Установлено, что более 50\% населения данной страны испытывали повышенное чувство тревоги и страха, при этом в 40\% случаев - в тяжелой форме [2], также регистрировались случаи суицида [50]. Число выписанных рецептов на анксиолитические препараты только за 1 мес. (с 15 февраля по 15 марта 2020 г.) выросло на 34,1\%, а назначение антидепрессантов и снотворных средств увеличилось на 18,6 и 14,8\% соответственно [2].

Согласно данным систематического обзора [55], у $25 \%$ больных возникают такие симптомы психических нарушений, как ажитация, панические атаки, психомоторное возбуждение, спутанность сознания, оглу- шение, сопор, кома, эпилептические приступы, требующие оказания неотложной специализированной помощи $[6,7,18,48]$.

\section{Зак^ючение}

Таким образом, несмотря на наличие гипотез, объясняющих взаимосвязь между неврологическими/ психическими расстройствами и новой коронавирусной инфекцией COVID-19, существуют единичные клинические исследования, обосновывающие указанные предположения. Несомненно, необходимы дальнейшие углубленные исследования поражения нервной и психической систем при COVID-19, что позволит дополнить имеющиеся на сегодняшний день сведения. Дальнейшее изучение взаимосвязи неврологических/ психических расстройств и COVID-19 должно включать не только регистрацию эпидемиологических данных, но и изучение механизмов патогенеза указанных состояний. Более совершенное понимание патогенеза неврологических и психических расстройств, обусловленных COVID-19, будет способствовать определению новых диагностических биомаркеров, среди которых, на наш взгляд, наибольшей перспективой обладают маркеры нейрогенного воспаления ввиду их существенной роли в регуляции ответа на экзо- и эндогненные факторы.

\section{ЛИТЕРАТУРА}

1. Баклаушев В.П., Кулемзин С.В., Горчаков А.А., и др. COVID-19. Этиология, патогенез, диагностика и лечение // Клиническая практика.—2020.T. 11.—№ 1.—C. 7-20.

2. Мосолов C.Н. Проблемы психического здоровья в условиях пандемии COVID-19 // Журнал неврологии и психиатрии им. С.С. Корсакова.— 2020.T. 120.— № 5.- - C. 7-15.

3. Нестеровский Ю.Е., Заваденко Н.Н. Головная боль и другие неврологические симптомы в структуре клинической картины новой коронавирусной инфекции (COVID-19) // Нервные болезни, 2020, № 2. С. 60-68 D0I: 10.24411/2226-0757-2020-12181

4. Сорокин М.Ю. Касьянов Е.Д. Структура тревожных переживаний, ассоциированных с распространением COVID-19: данные онлайн-опроса // Вестник РГМУ, 2020, № 03. C. 77-85. D0I: 10.24075/vrgmu.2020.030

5. Ширяев 0.Ю. Взаимосвязь семейного и личного перфекционизма студента: гендерный аспект / 0.Ю. Ширяев, М.В. Ларских // Вестник ВГУ Серия: Проблемы высшего образования. - 2016. — № 2.- С. 12-15

6. Asadi-Pooya A.A., Simani L. Central nervous system manifestations of COVID-19: A systematic review // NeurolSci. 2020; 413: 116832. doi: 10.1016/j. jns.2020.116832.

7. Ahmad I., Rathore F.A. Neurological manifestations and complications of COVID-19: A literatu-re review // ClinNeurosci. 2020; 77:8-12. doi: 10.1016/j. jocn.2020.05.017.

8. Baig A.M., Khaleeq A., Ali U., Syeda H. Evidence of the COVID-19 virus targeting the CNS: tissue distribution, host-virus interaction, and proposed neurotropic mechanisms // ACS ChemNeursci. 2020; 11(7): 995-998. doi: 10.1021/acschemneuro.0c00122.

9. Bolay H., Reuter U., Dunn A.K., Huang Z., Boas D.A., Moskowitz M.A. Intrinsic brain activity triggers trigeminal meningeal afferents in amigraine model // Nature Medicine, 2002, № 8(2):136-42.

10. Borges do Nascimento I.J., Cacic N., Abdulazeem H.M., vonGroote T.C., Jayarajah U., Weerasekara I., Esfahani M.A., Civile V.T., Marusic A., Jeroncic A., Carvas N. Jr., Pericic T.P., Zakarija-Grkovic I., Guimarães S.M., Bragazzi N.L., Bjorklund M., Sofi-Mahmudi A., Altujjar M., Tian M., Arcani D.M.C., O'Mathúna D.P., Marcolino M.S. Novel coronavirus infection (COVID-19) in humans: a scoping review and meta-analysis/ / Journal of Clinical Medicine 2020 Mar;9(4):941.

11. Brann D.H., Tsukahara T., Weinreb C., et al. Non-neuronal expression of SARS-CoV-2 entry genes in the olfactory system suggests mechanisms underlying COVID-19-associated anosmia // bioRxiv. 2020;2020.03.25.009084. doi:10.1101/2020.03.25.009084.

12. Bridwell R., Long B., Gottlieb M. Neurologic Complications of COVID-19. Am.J. Emerg. Med., 2020. doi: 10. 1016/j.ajem.2020.05.024. 
13. Brooks S.K., Webster R.K., Smith L.E., Woodland L., Wessely S., Greenberg N et al. The psychological impact of quarantine and how to reduce it: rapid review of the evidence // Lancet. 2020; 395(10227):912-920.

14. Butowt R., Bilinska K. SARS-CoV-2: olfaction, brain infection, and the urgent need for clinical samples allowing earlier virus detection // ACS ChemNeurosci. 2020;11(9):1200-1203. doi: 10.1021/acschemneuro.0c00172

15. Cappello F. COVID-19 and molecular mimicry: The Columbus' egg? // ClinNeurosci. 2020; 77:246. doi: 10.1016/j.jocn.2020.05.015.

16. Cardona G.C., Quintana Pájaro L.D., Quintero Marzola G.C., et al. Neurotropism of SARS-CoV 2: mechanisms and manifestations // Neurol Sci. $2020 ; 412: 116824$. doi: 10.1016/j.jns.2020.116824.

17. Chan J.F.-W., Yuan S., Kok K.H., To K.K.W., Chu H., Yang J., et al. A familial cluster of pneumonia associated with the 2019 novel coronavirus indicating person-toperson transmission: a study of a family cluster // The Lancet. 2020; 395 (10223): 514-23. Available from: https://doi.org/10.1016/50140-6736(20)30154-9

18. Colizzi M., Bortoletto R., Silvestri M., Mondin F. Medically unexplained symptoms in the times of Covid-19 pandemic: A case-report // Brain, Behavior, and Immunity. 2020; 5:100073. doi: 10.1016/ j.bbih.2020.100073.

19. Das G., Mukherjee N., Ghosh S. Neurological insights of COVID-19 pandemic// ACS ChemNeurosci. 2020:11(9):1206-1209. doi: 10.1021/acschemneuro.0c00201.

20. Desforges M., Le Coupanec A., Dubeau P., et al. Human Coronaviruses and other respiratory viruses: underestimated opportunistic pathogens of the central nervous system? // Viruses. 2019; 12(1):14. doi: 10.3390/v12010014.

21. Dixon L., Varley J., Gontsarova A., Mallon D., et al. COVID-19-related acute necrotizing encephalopathy with brain stem involvement in a patient with aplastic anemia // NeurolNeuroimmunoINeuroinflamm. 2020;7(5): e789. doi: 10.1212/NXI.00000000000000789.

22. Edvinsson L., Haanes K.A., Warfvinge K. Does inflammation have a role in migraine? // NatureReviews. Neurology, 2019 Aug; 15(8):483-90.

23. Finsterer J., Stollberger C. Causes of Hypogeusia/Hyposmia in SARSCoV2 infected patients // Med Virol. 2020; 10.1002/jmv.25903. doi: 10.1002/ jmv.25903.

24. Gales S., Merchant R.M., Lurie N. The mental health consequences of COVID-19 and physical distancing: the need for prevention and early intervention // JAMA Intern Med. 2020. [Ahead of print, published online 10 April 2020]. doi:10.1001/jamainternmed.2020.1562

25. Gandhi S., Srivastava A.K., Ray U., Tripathi P.P. Is the Collapse of the Respiratory Center in the Brain Responsible for Respiratory Breakdown in COVID-19 Patients? // ACS ChemNeuro- sci. 2020;11(10):1379-1381. doi: 10.1021/acschemneuro.0c00217.

26. Garg S., Garg M., Prabhakar N., Malhotra P., Agarwal R. Unraveling the mystery of Covid-19 Cytokine storm: From skin to organ systems // DermatolTher. 2020 Jun 19: e13859. doi: 10.1111/dth.13859.

27. Giacomelli A., Pezzati L., Conti F, et al. Self-reported olfactory and taste disorders in SARS-CoV-2 patients: A cross-sectional study. Clin Infect Dis. 2020 ; ciaa330. doi: $10.1093 /$ cid/ciaa330.

28. Headache Classification Committee of the International Headache Society (IHS) //The International Classification of Headache Disorders. 3rd ed. Cephalalgia 2018; 38(1):1-211.

29. Huang (/, Wang Y/, Li X/, et al. Clinical features of patients infected with 2019 novel coronavirus in Wuhan, China // Lancet. 2020; 395(10223):497-506. doi: 10.1016/S0140-6736(20)30183-5.

30. Hung E.C., Chim S.S., Chan P.K., et al. Detection of SARS coronavirus RNA in the cerebrospinal fluid of a patient with severe acute respiratory syndrome // Clin Chem. 2003; 49(12): 2108-2109. doi: 10.1373/clinchem.2003.025437.

31. Kandemirli S.G., Dogan L., Sarikaya Z.T., et al. Brain MRI findings in patients in the intensive care unit with COVID-19 infection // Radiology. $2020 ; 201697$. doi:10.1148/radiol.2020201697.

32. Lai J., Ma S., Wang Y., Cai Z., Hu J., Wei N., et al. Factors Associated With Mental Health Outcomes Among Health Care Workers Exposed to Coronavirus Disease 2019 // JAMA Netw Open. 2020; 3 (3): e203976. D0l: 10.1001/jamanetworkopen.2020.3976.

33. Lau K.-K., Yu W.-C., Chu C.-M., Lau S.-T., Sheng B., Yuen K.-Y. Possible central nervous system infection by SARS coronavirus // Emerg. Infect. Dis., 2004;10(2):342344.doi:10.32 <01/eid1002.030638.

34. Le Coupanec A., Desforges M., Meessen-Pinard M., et al. Cleavage of aneuroinvasive human respiratory virus spike glycoprotein by proproteinconvertases modulates neurovirulence and virus spread within the central nervous system // PLOSPathog. 2015;11(11): e1005261. doi: 10.1371/journal.ppat.1005261.

35. Lechien J.R., Chiesa-Estomba C.M., Place S, et al.; COVID-19 Task Force of YO-IFOS. Clinical and epidemiological characteristics of 1,420 European patients with mild-to-moderate Coronavirus Disease 2019 // InternMed. 2020;10.1111/ joim.13089. doi: 10.1111/joim.13089/

36. Mao L., Jin H., Wang M., Hu Y., Chen S., He Q., Chang J., Hong C., Zhou Y., Wang D., Miao X., Li Y., Hu B. Neurologic manifestations of hospitalized patients with coronavirus disease 2019 in Wuhan, China // JAMA. Neurology 2020 Apr; 77(6):1-9.

37. McAbee G.N., Brosqol Y., Pavlakis S., et al. Encephalitis associated with COVID-19 infection in 11 year-old child // PediatricNeurology. 2020. doi: 10.1016/j. pediatrneurol.2020.04.013.

38. Mehta P., McAuley D.F., Brown M., et al. COVID-19: consider cytokine storm syndromes and immunosuppression // Lancet. 2020; 395(10229): 1033-1034. doi:10.1016/S0140-6736(20)30628-0.

39. Misra D.P., Agarwal V., Gasparyan A.Y., Zimba 0. Rheumatologists' perspective on coronavirus disease 19 (COVID-19) and potential therapeutic targets // ClinRheumatol. 2020; 39(7): 2055-2062. doi: 10.1007/s10067-020-05073-9.

40. Mori I. Transolfactoryneuroinvasion by viruses threatens the human brain. ActaVirol. 2015;59(4):338-349. doi: 10.4149/av_2015_04_338.

41. Moriguchi T., Harii N., Goto J., et al. A first case of menin-getis/encephalitis associated with SARS-Coronavirus-2 // Int J Infect Dis. 2020; 94:55-58. doi: 10.1016/j.jijid.2020.03.062.

42. Niazkar H.R., Zibaee B., Nasimi A., Bahri N. The neurological manifestations of COVID-19: a review article // Neurol Sci. 2020; 1-5. doi: 10.1007/s10072-02004486-3. 
43. Obiefuna S., Donohoe C. Neuroanatomy, Nucleus Gustatory. In: StatPearls [Internet]. Treasure Island (FL): StatPearls Publishing; 2020.

44. Panariello A., Bassetti R., Radice A., et al. Anti-NMDA receptor encepha-litis in a psychiatric Covid-19 patient: a case // Brain Behav Immun. 2020 ; 87:179-181. doi: 10.1016/j.bbi.2020.05.054.

45. Paniz-Mondolfi A., Bryce C, Grimes Z, et al. Central nervous system involvement by severe acute respiratory Syndrome Coronavirus-2 (SARSCoV-2). J MedVirol. 2020;92(7):699-702. doi: 10.1002/jmv.25915.

46. Radmanesh A., Derman A., Lui Y.W., et al. COVID-19-associated diffuse leukoencephalopathy and microhemorrhages // Radiology. 2020; 202040. doi: 10.1148/radiol.2020202040.

47. Radmanesh F., Rodriguez-Pla A., Pincus M.D., Burns J.D. Severe cerebral involvement in adult-onset hemophagocyticlymphohistiocytosis // ClinNeurosci. 2020; 76:236-237. doi: 10.1016/j.jocn.2020.04.054.

48. Rogers J.P., Chesney E., Oliver D., et al. Psychiatric and neuropsychiatric presentations associated with severe coronavirus infections: a systematic review and meta-analysis with comparison to the COVID-19 pandemic // Lancet Psychiatry. 2020; 7(7): 611-627. doi: 10.1016/S2215-0366(20)30203-0.

49. Rossi R., Socci V., Talevvi D., Mensi S., Niolu C., Pacitti F. et al. COVID19 pandemic and lockdown measure impact on mental health among the general population in Italy // MedRxiv preprint. [Ahead of print, published online 14 April 2020]. doi:10.1101/2020.04.09.20057802

50. Schwati B.J. New Poll: COVID19 Impacting mental well-being: American feeling anxious, especially for loved ones. APA News releases. [Published online 25 March 2020]. [Electronic resource]. URL: https://www.psychiatry.org/newsroom/news-releases/new-poll-covid 19-impacting-mental-well-beingamericans-feeling-anxious-especially-for-loved-ones-older-adultsare-less-anxious

51. Singh A.K., Bhushan B., Maurya A., et al. Novel coronavirus disease 2019 (COVID-19) and neurodegenerative disorders // DermatolTher. 2020; e13591. doi: 10.1111/dth.13591.

52. Sotoca J., Rodríguez-Álvarez Y. COVID-19-associated acute necrotizing myelitis // NeurolNeuroimmunolNeuroinflamm. 2020; 7(5): e803. doi: 10.1212/ NXI.0000000000000803.

53. Statement on the second meeting of the International Health Regulations (2005) Emergency Committee regarding the outbreak of novel coronavirus (2019-nCoV). World Health Organization (WH0), 2020. Available from (assessed Feb 15, 2020): https:// www.who.int/news-room/detail/30-01-2020-statement-on-the-second-meeting-of-the-international-health-regulations(2005)-emergency-committee-regarding-the-outbreak-of-novel-coronavirus-(2019-ncov).

54. Tostmann A., Bradley J., Bousema T., Teun B., Yiek W.K., Holwerda M., Bleeker-Rovers C., ten Oever J., Meijer C., Rahamat-Langendoen J., Hopman J., van der Geest-Blankert N., Wertheim H. Strong associations and moderate predictive value of early symptoms for SARS-CoV-2 test positivity among healthcare workers, the Netherlands, March 2020 // Eurosurveillance, 2020 Apr; 25(16):2000508.

55. Troyer E.A., Kohn J.N., Hong S. Are we facing a crashing wave of neuropsychiatric sequelae of COVID-19? Neuropsychiatric symptoms and potential immunologic mechanisms // Brain Behav Immun. 2020; 87:34-39. doi: 10.1016/j.bbi.2020.04.027

56. Vaira L.A., Deiana G., Fois A.G., et al. Objective evaluation of anosmia and ageusia in COVID-19 patients: Single-center experience on 72 cases // Head Neck. 2020; 42(6):1252-1258. doi: 10.1002/hed.26204.

57. Vavougios G.D. Host Proteases as Determinants of Coronaviral Neurotropism and Virulence // Brain Behav. Immun., 020; S0889-1591(20)30464-5. doi:10.1016/j.bbi.2020.04.010.

58. «WHO Director-General's opening remarks at the media briefing on COVID-19». World Health Organization (WH0) (Press release), 11 March 2020. Archived from the original on 11 March 2020. Available from: https://www.who.int/dg/speeches/detail/who-director-general-s-opening-remarks-at-the-media-briefingon-covid-19-11-march-202.

59. Wu P., Duan F., Luo C., et al. Characteristics of ocular findings of patients with coronavirus disease 2019 (COVID-19) in Hubei Province, China // JAMA Ophthalmol. 2020; 138(5):5 < 75-578. doi: 10.1001/jama ophthalmol.2020.1291.

60. Wu Y., Xu X., Chen Z., Duan J., Hashimoto K., Yang L et al. Nervous system involvement after infection with COVID-19 and other coronaviruses // Brain Behav Immun. 2020. [Publishedonline 28 March 2020]. doi:10.1016/j.bbi.2020.03.031

61. Wu Y., Xu X., Chen Z., et al. Nervous system involvement after infectionwith COVID-19 and other Coronaviruses // Brain Behav Immun. 2020;87:18-22. doi:10.1016/j.bbi.2020.03.031.

62. Xu H., Zhong L., Deng J. et al. High expression of ACE2 receptor of 2019-nCoV on the epithelial cells of oral mucosa // Int J 0ral Sci. 2020; 12(1):8. doi:10.1038/ s41368-020-0074-x

63. Ye M., Ren Y., Lv T. Encephalitis as a clinical manifestation of COVID-19 // Brain Behav Immun. 2020; S0889-1591(20)30465-7. doi: 10.1016/j.bbi.2020.04.017.

(с Гуменюк Леся Николаевна ( lesya_gymenyuk@mail.ru ), Узбекова Лейла Джавадовна ( leila1998.999@mail.ru ),

Лебедева Анна Михайловна ( anna96lebedeva@yandex.ru).

Журнал «Современная наука: актуальные проблемы теории и практики» 